\title{
Development an Elevator Emergency Call Transmission System
}

\author{
Lee Yong Hui ${ }^{1}$, Kim Hyun $\mathrm{Gi}^{2}$ \\ ${ }^{1}$ Shinsung University, Chief of Information Service Center, \\ DaehackRo1 Jungmimyun, DanginCity, ChungNam, Korea, 343-861, \\ ${ }^{2}$ Gangdong University, Dept., of Smart Phone, \\ DaehackRo278 Gamgok-Myun, Eunsung-Gun, ChungBuk, Korea, 467-900, \\ ${ }^{1}$ lyhkpi@shinsung.ac.kr, ${ }^{2}$ king@gangdong.ac.kr
}

\begin{abstract}
It may be difficult to request an emergency rescue with a mobile communication handset in a sealed space like an elevator in the case of an emergency situation, due to electromagnetic waves shielding within the elevator. The call button installed in an elevator is mostly connected with management office or security room, and a problem that immediate rescue becomes difficult arises during the absence of an administrator or a guard. In this context, the development of a technology enabling to request rescue to the administrator or guard even during his/her absence is required. This paper enables location information to be sent via SMS and phone call to the mobile phone of the person concerned registered with the emergency call management system immediately, if someone presses the emergency call button in an elevator.
\end{abstract}

Keywords: SMS, LMS, emergency call, RS232, RS485

\section{Introduction}

The installation of an elevator has become a means for essential vertical transportation in everyday life, rather than a concept of a means for transportation according to population's concentration to city and the trend of high rise and large-sized buildings. The elevator originates from a pulley used to draw water from a well by Greek Archimedes in around 200 BC. The modern type of an electric powered elevator was manufactured by German Siemens in 1880. Technologies are advancing to meet promptness, pleasantness, stability, economic efficiency, convenience and design required by customers in various of walks of life in terms of the recent technology trend of elevators. The safety accidents of elevators, however, increase, according to the use of elevators. As mobile phones are generally used, the population using text message service recently surges. SMS (Short Message Service) is widely used, since the content is immediately delivered upon it is transmitted, unlike email. Text message services are divided into LMS (Long Message Service), through which text with 80 characters or more can be sent, and SMS, through which text with 80 characters or under can be sent. In emergency call, the SMS with 80 characters or under is necessary [1-3]. This paper develops an emergency call system [4-7], through which a rescue request can be made with short message composed of maximum 80 characters using such a characteristic of SMS, and an EECTS (Elevator Emergency Call Transmission System), through which calling is possible with the administrator concerned. For hardware design, PIC16FF73 circuit was designed using an OrCAD program and the PCB was manufactured with PCB Artwork. Hardware operation software was produced with $\mathrm{C}$ language for management room, security 
room and modem communications. An integrated control system including an administrator screen and a repairing company screen was manufactured using Visual Basic.

\section{Elevator Accident and Emergency Call System}

\subsection{Elevator Accident}

An elevator accident occurs, due mainly to the following reasons: Elevator does not stop, where the door needs to be normally open or the door is not open, although, the elevator stops on the concerned floor; The elevator is operated with its door open; The elevator is not operated to the floor of call or to the instructed floor; The operation of elevator halts, because of power failure. From the statistics of elevator accidents occurring in Korea during 2000 and 2012 as shown in Figure 1, the number of accidents continually rises, according to the increase of elevators used.

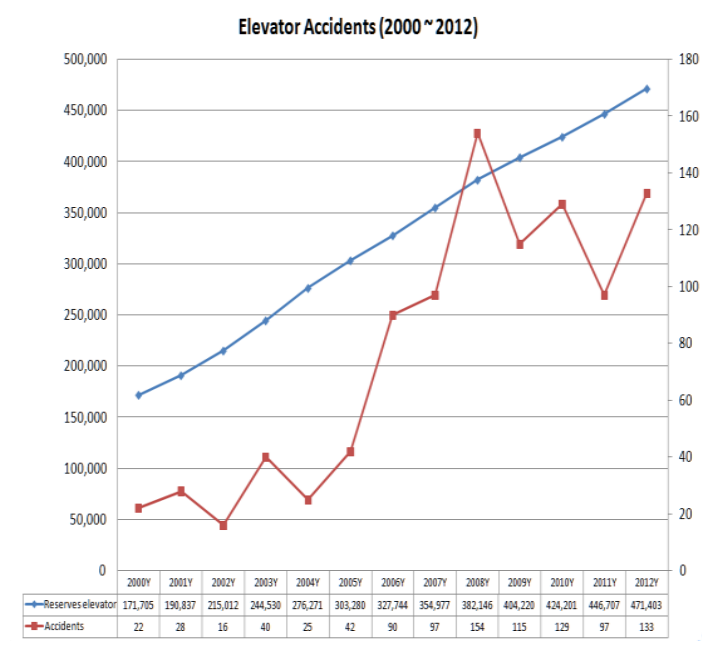

Figure 1. Statistics of Yearly Elevator Accident Status

(Source: Korea Elevator Safety Institute)

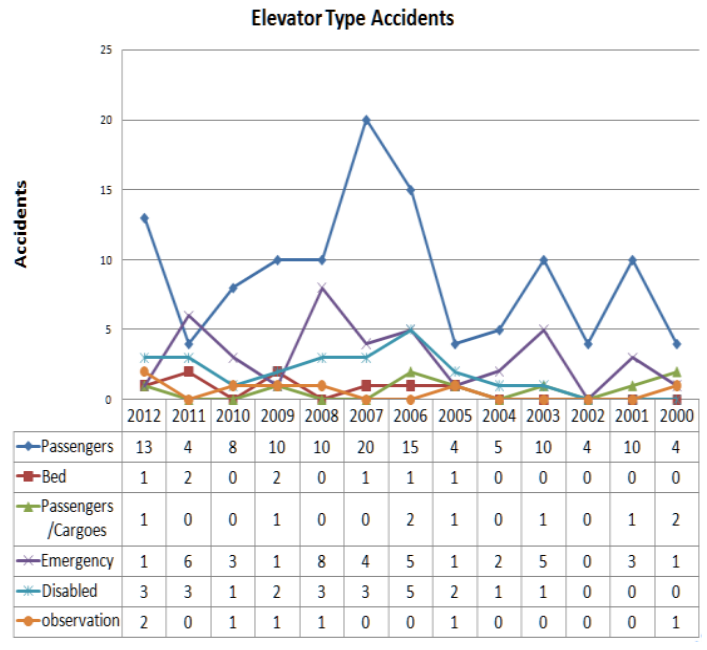

Figure 2. Accident Status by Elevator Type

(Source: Korea Elevator Safety Institute)

Figure 2 demonstrates accident status by elevator type, and the elevators for passengers accounted for the highest with $16 \%$ out of the total accidents. From the statistics of duration of being locked in an elevator, due to elevator breakdown, 15 less than 30 minutes accounted for about half, which is the most. All in all, a passenger elevator emergency call transmission system, through which accident status can be informed upon accident, when one presses the emergency call button, is urgently needed.

\subsection{System Composition}

In the existing elevator system Figure 3, if a person presses an emergency bell, the interphone rings in the security room, since $12 \mathrm{~V}$ of voltage is loaded to the signal wire. In reality, however, a guard is not always in the security room 24 hours a day, but conducts various other duties including patrol and cleaning; therefore, he/she cannot always receive an emergency signal on time via the interphone. Also, the system has a demerit that much time is required to contact the personnel in charge of elevator in order to take a proper action, because a warning (buzzer) is activated to both security room and management room. If so 
much time is required, people who are confined in the elevator, due to an elevator accident, will face with extreme fear.

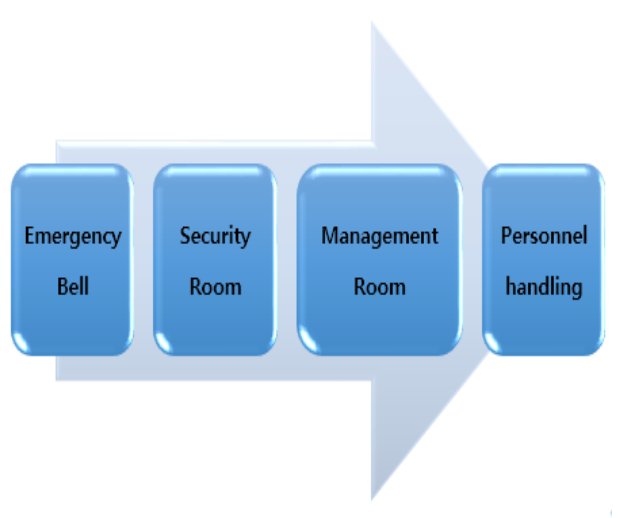

Figure 3. Existing Emergency Call System
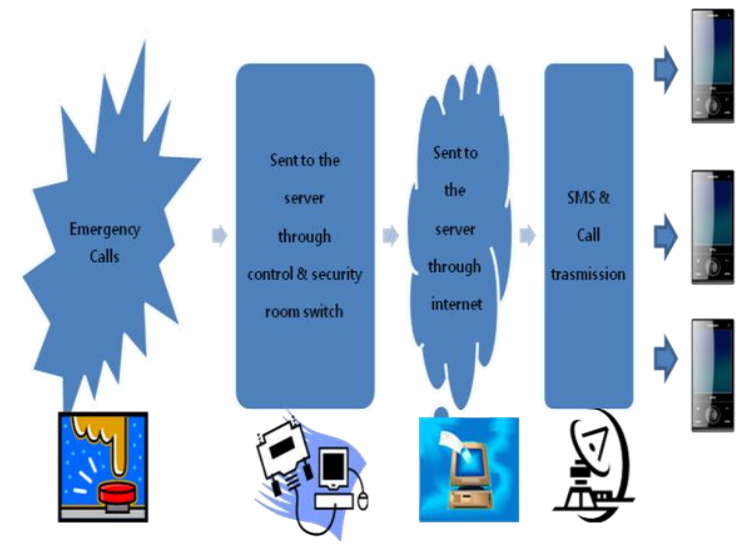

Figure 4. Suggested EECTS System

To solve such a problem, an emergency call system plus an integrated management system, that is, elevator emergency call transmission system (EECTS), was developed as demonstrated in Figure 4. When an emergency call signal of a building takes place, the elevator's signal is connected with the server concerned on the Internet through the equipment installed in the security room and management room. In the server, the information of an elevator administrator and security rooms registered in advance is managed in database. Through this, if an emergency signal is received, the information of the emergency caller (emergency call location information) is immediately transmitted to the personnel registered with the server via SMS. Of course, the system is set up, separately from the existing interphone line, and thus, they do not influence each other in operation. Even if there is a trouble on the wired Internet, the signal can be connected with the server via the wireless Internet. Also, direct call equipment has been embodied between a person locked in the elevator and the personnel in charge of elevator.

\subsection{Development Environment}

This system can be additionally installed using the existing facility to the fullest without installing the system anew or huge remodeling of the existing facility. First, security room's controller receiving elevator emergency bell signal coming to the security room or management room is developed. And the controller for management room is built to collect data from the security room to the management room When an emergency signal comes from the elevator, the security room sends it to the management room by tagging an emergency tag signal. In doing so, RS485 communication is used. Each security room can tell 9 bell signals and the management room can manage 9 security rooms: therefore, maximum 81 elevators can be simultaneously managed.

\subsection{Communication Protocol}

RS485 communication is regulated with electrical specifications by EIA (Electronic Industries Association) and a half duplex transmission support mode and TXD (Transmit Data) signal are connected or short-circuited to multipoint bus as shown in Figure 5. RXD 
(Receive Data) signal is also controlled by connection and short-circuit, depending on mode. For signal wire, two lines are necessary for one signal wire and they are indicated by dividing into "+" and "-." As the TXD and RXD signal wires of UART (Universal Asynchronous Receiver Transmit), however, are jointly used by multipoint bus, one master is used by being divided into multipoint output in the case of output, or multipoint input in the case of input. RS232 communication is regulated in the EIA as Recommend Standard 232, and the regulation is the interface regulation between DTE (Data Terminal Equipment) and DCE (Data Communication Equipment). Although, RS232 defined electrical acceptance, control hand shacking, transmission speed, signal stand-by time and impedance acceptance, the format and content of transmitted data are not designated, and the content on the interface between DTE is not included. RS232 is asynchronous system, and its motion mode is a single-ended mode and uses Full Duplex transmission mode composed of one transmission line per one signal transmission. Start bit and stop bit are tagged to the beginning and end of data: start bit indicates the beginning of data, while stop bit indicates the end of data. When data is transmitted, star bit is always simultaneously transmitted, and data transmission is informed to the receiving party with start bit value of 0 .

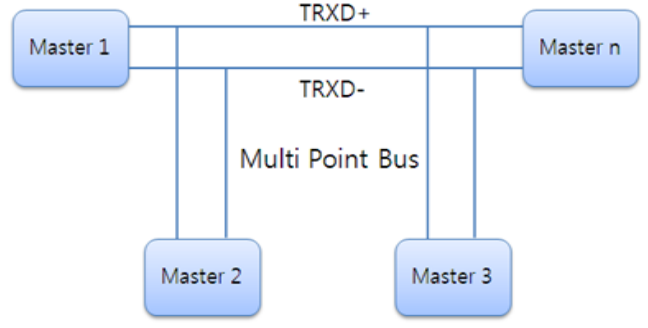

Figure 5. RS485 Cable Connection Diagram

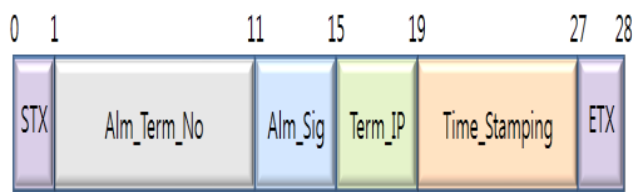

Figure 6. Data format for Emergency Signal
Transmission and Reception

The data, sent from management room's warning terminal device from the transmission party of ITU to the server of the receiving party, composed the data format for emergency reception sent from ux-net to the server with a total of 28 bytes using ASCII code standardized by ISO within ITU (International Telecommunication Union). For the data format composition, this study allocated 1 byte for transmission control text STX, 10 bytes for the warning terminal serial number of the receiving party registered by a user, 4 bytes for emergency signal, 4 bytes for terminal device IP and 8 bytes for temporary emergency signal occurrence. Also, 1 byte was allocated for transmission control text ETX indicating the end of data. The data format of emergency signal transmission was composed as shown in Figure 6. 


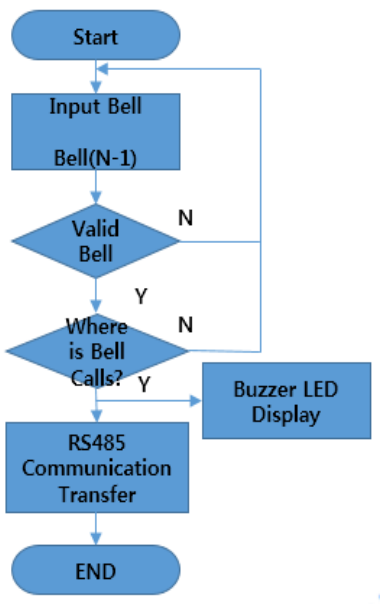

Figure 7. Emergency Signal Communication Flow Chart of Security Room

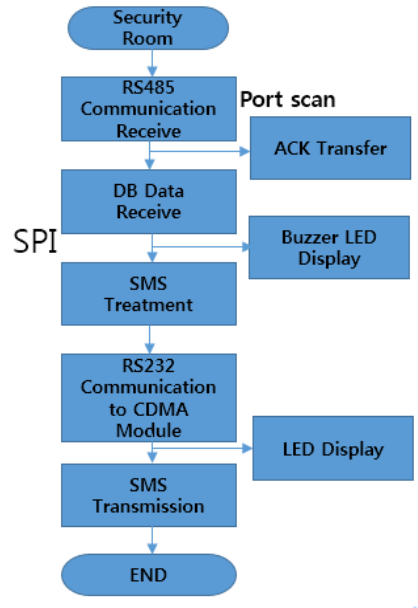

Figure 8. Emergency Signal Communication Flow Chart of Management Room

Figure 7 shows the communication flow chart of security room. When emergency input signal bell of a certain location is received, whether it is a valid signal is checked. If the bell is valid, an inspection on which location the bell started is made. Once the location is checked, buzzer sounds. At the same time, the signal is transmitted to the management room through RS485 communication. Figure 8 demonstrates the emergency signal communication flow chart of the management room sending the signal coming from security room as SMS transmission signal. When a signal is received from the security room through RS485 communication, port scan is conducted, ACK transmission is undertaken and it is received from the database. The received signal sounds buzzer through SPI communication and SMS is processed. Through RS232 communication, the SMS is sent to CDMA [8-10], and then it is finally received. Ultimately, EECTS is operated via direct call equipment.

\section{Conclusion}

This paper develops EECTS (Elevator Emergency Call Transmission System) through which an emergency call information can be immediately transmitted and received with mobile phone to and from the personnel in charge of the elevator, and thus, an emergency calling can be made with the elevator, in case someone presses an emergency call bell within an elevator. For communication mode, RS485 communication is used by utilizing the existing interphone line. The security room can tell 9 signals maximum. The management room can manage 9 security rooms, and thus, a total of 81 elevators can be managed. Such an EECTS can be widely used in the fields where emergency situation may occur, as well as in an elevator.

\section{References}

[1] Kabadi, G. S.; Mwanyika, H.; de Savigny, D. Innovations in monitoring vital events: a scalable intervention using mobile phone messaging (SMS) support for vital registration coverage (The Lancet, Vol.381//SUP2, [2013]) [SCI,SCIE,SCOPUS]

[2] Chun, W.-S.; Park, D.-W. A Study on the Forensic Data Extraction Method for SMS, Photo and Mobile Image of Google Android and Windows Mobile Smart Phone (COMMUNICATIONS IN COMPUTER AND INFORMATION SCIENCE, No.310, [2012]) 
[3] Car, N. J.; Christen, E. W.; Hornbuckle, J. W.; Mo Using a mobile phone Short Messaging Service (SMS) for irrigation scheduling in Australia - Farmers' participation and utility evaluation (Computers and electronics in agriculture, Vol.84, [2012]) [SCIE,SCOPUS]

[4] Ottaiano, L.; Casavecchia, R.; Fiorenza, G. Emergency Management: An Advanced Trouble Call System (INTERNATIONAL CONFERENCE ON ELECTRICITY DISTRIBUTI, Vol.19 No.1-2, [2007])

[5] Lee Yong Hui, Kim Hyun Gi., Short Message Service Transmission System(Advanced Science and Technology Letters Vol. 42, pp.117-120. (Mobile Wireless [2013])

[6] Stats, W.L.; Lorenc, D.P.; Zhang, Z.; Huwe, E.L.; IMECE2010-40681 Design of a Wireless, Passive, SingleUse Emergency Call System (INTERNATIONAL MECHANICAL ENGINEERING CONGRESS, Vol.2, [2010])

[7] Barrientos, F.; Sainz, G. Interpretable knowledge extraction from emergency call data based on fuzzy unsupervised decision tree (Knowledge-based systems, Vol.25 No.1, [2012]) [SCI,SCIE,SCOPUS]

[8] Madkour, M. F.; Mohamed, N. A. A New Channel Estimation Technique for any CDMA-Based Communications System (PROCEEDINGS OF THE IEEE MIDWEST SYMPOSIUM ON CIRCU, Vol.46 No.3, [2003])

[9] Cai, X.-D.; Sun, Y.; Akansu, A. N. Performance of CDMA Random Access Systems With Packet Combining in Fading Channels (IEEE TRANSACTIONS ON WIRELESS COMMUNICATIONS, Vol.2 No.3, [2003]) [SCI,SCIE,SCOPUS]

[10] Chamberland, J.-F.; Veeravalli, V. V. Decentralized Dynamic Power Control for Cellular CDMA Systems (IEEE TRANSACTIONS ON WIRELESS COMMUNICATIONS, Vol.2 No.3, [2003]) [SCI,SCIE,SCOPUS]

\section{Authors}

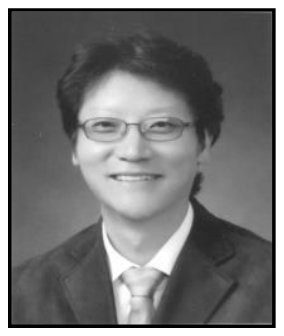

Lee Yong Hui received his $\mathrm{BS}$, MS and $\mathrm{PhD}$ in Electronic Engineering from CheongJu University, CheongJu, Rep. of Korea, in 1989, 1991 and 2001, respectively. He worked at HYNIX Semiconductor ULSI LAB from 1995 to 2002. Since 2002, he has been dept, of Computer Application and Chief of Information Service Center at Shinsung University, Dangin, Rep. of Korea. His current research interests include computer control, microprocessor, web programming, RFID, server, network and information security.

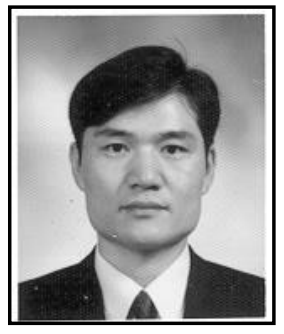

Kim Hyun Gi received his $\mathrm{BS}, \mathrm{MS}$ and $\mathrm{PhD}$ in Information Communication from HoSeo University, Cheonan, Rep. of Korea, in 1986 and 1992, respectively. He received his $\mathrm{PhD}$ in Electronic Engineering from CheongJu University, CheongJu, Rep. of Korea, in 2002. Since 1996, he has been dept, of Smart Phone, Gangdong University, Eunsung, Rep. of Korea. His current research interests include Microprocessor, App Programming, smart phone, real time processing and computer network. 